Kiran Niraula, MBBS

Department of Neurosurgery

King Edward Medical University

Lahore, Pakistan

Muhammad Irfan, MD, MS

Department of Neurosurgery

King Edward Medical University

Lahore, Pakistan

Chandra P Limbu, MBBS, MS

Department of Neurosurgery

Annapurna Neurological Institute and Allied

Sciences

Kathmandu, Nepal

Raj Kumar KC, MBBS, MS

Department of Neurosurgery

Nepal Medical College

Kathmandu, Nepal

Muhammad A Shaheen, MBBS, FCPS

Department of Neurosurgery

King Edward Medical University

Lahore, Pakistan

Megha Ghimire, MBBS

Department of Pediatrics

King Edward Medical University

Lahore, Pakistan

Address for Correspondence:

Kiran Niraula, MBBS

Department of Neurosurgery

King Edward Medical University, Pakistan

Email: nirkiran@yahoo.com

Received, 13 July, 2017

Accepted, 24 July, 2017

\section{Pattern of Neurological Improvements in Patient with Lumbar Disc Herniation after Microdiscectomy: Experience at the Fourth Oldest Western Medical Facility in South Asia}

The pattern of improvement in Neurological status after disc surgery is different. The chronology of improvement in Medical Research Council (MRC) scores, sensory status and improvement in Straight Leg Raise (SLR) test degrees is beneficial in management part to surgeons, relatives and the patients.

To assess pattern of neurological outcomes in patients with lumbar disc herniation after microdiscectomy interms of muscle power, sensory status and SLR.

A Quasi experimental study comprising 70 consecutive cases though non-probability purposive sampling technique of both the sexes admitted in Neurosurgery department, Mayo Hospital operated for the 1st time for any disc pathology with no other spinal lesions giving consent themselves or though legal guardians was conducted. Pain for leg and back was measured pre and post-operatively was done by VAS which had 42 days of follow up. Standard Neurological examinations were conducted pertaining to muscle power (by MRC), sensory status and SLR test pre and post-operatively. Variables according to their nature were expressed in the form of Mean $\pm \mathrm{SD}$, Median (Range) and Frequency (percentage). Mc Neumer's chi square test and paired $t$ test were used to see association between preoperative and post-operative Neurological status depending on their nature viz: qualitative or quantitative respectively in SPSS version 15.

Out of 70 patients $74 \%$ were male and $26 \%$ were females. Mean \pm SD of patients was $37.6 \pm 13.0$ years. Majority were Laborers after housewives. Illiterates, Poor lifting techniques were the most common characteristics in the respective headings of education and employment. Most common level of disc herniation was L4-L5, L5S1 level (96\%) where Prolapse and extrusion were most common MRI findings. As compared to pre-operative (3.4) muscle power 1 st and 42 nd day power were respectively 4.0 and $4.7(p=0.001)$. Pre-operatively only $32(45.7 \%)$ 
had normal sensation which improved to 38 (54.3\%) and $51(72.9 \%)$ respectively in 1 st and 42 nd day of surgery $(\mathrm{p}=0.001)$. Pre-operative mean SLR improved to 98.6 degrees in 1st POD and continued to be the same till 42nd day ( $p=0.001)$. All the MRC findings, sensory status and SLR values in each post-operative days were statistically significant with the baseline by paired t test $(p=0.001)$. MRC and Sensory status had same pattern of improvement $(r=0.0 . p=0.04)$ unlike SLR which total improvements were see in 1st POD itself.

In conclusion, muscle power and sensory improvement follows same improvement pattern whereas maximum SLR improves in the 1st POD itself.

Key Words: lumbar disc herniation, MRC, pattern of improvement, sensation, SLR

$\mathrm{T}$ The standard surgical treatment of lumbar disc herniation has been open discectomy, ${ }^{15}$ but there has been a trend towards minimally invasive procedures. The open discectomy is traditionally done by mobilizing the muscles laterally off the spinous process and lamina using a unilateral retractor. A minimally invasive microdiscectomy involves dilating the paraspinous muscles and using tubular retractors without stripping the muscles off the spinous processes. ${ }^{10}$ It is thought that dilating the muscles rather than stripping the muscles decreases surgical morbidity., ${ }^{4,6}$ The purported benefit of the minimally invasive approach is that it would allow patients to recover more quickly because of less tissue trauma. ${ }^{18}$

While a minimally invasive approach may seem ideal, there is a learning curve associated with execution of the procedure, patient safety, and outcome. ${ }^{14}$ Although minimally invasive microdiscectomies are appealing to many patients, its superiority over standard open discectomy has not been conclusively demonstrated. $\mathrm{Wu}$ et al. concluded in their restrospective study that minimally invasive microdiscectomy affords optimal post-operative outcomes and is superior when compared to open discectomy. ${ }^{23}$

Harrington and French found that perioperative parameters were similar. In their study, the minimally invasive group had less narcotic usage and shorter length of stay, but they did not conclude that one technique was better than the other. ${ }^{8}$ Cole and Jackson showed that obese individuals undergoing minimally invasive microdiscectomies had decreased incision lengths and may have a reduced infection rates. ${ }^{5}$ However, German et al. ${ }^{6}$ and Porchet et al. ${ }^{14}$ show that there is no significant difference. Ryang et al. found, similar to our results, that operating times with either minimally invasive or open discectomies were not significantly different. ${ }^{19}$ German et al. showed that patients who underwent minimally invasive microdiscectomies had about half the length of stay compared to patients who underwent open discectomies ( 0.84 days vs. 1.43 days). ${ }^{6}$ Although shorter hospital stays may lead to lower medical costs, ${ }^{1}$ McLoughlin and Fourney analyzed the depth of the learning curve involved in minimally invasive lumbar microdiscectomies and found that it took about 15 cases for spine surgeons to be comfortable with, and proficient at, the technique. Operative times and complications for minimally invasive microdiscectomy were reduced as the surgeon became more experienced with the technique. ${ }^{13}$ An advantage that minimally invasive surgery may offer is the psychological effect that newer and more advanced technology is being used. ${ }^{6}$ This may allow patients to believe that minimally invasive microdiscectomy is superior. Many patients specifically request and want only minimally invasive surgery. German et al. found that minimal and open discectomy had similar perioperative results; the difference was significant although of modest clinical significance; but in this study comparison was made between two modalities of microdiscectomy and not with standard discectomy. ${ }^{6}$ One study showed there is significant perioperative bleeding opting for microdiscectomy. The same study emphasized it is superior in teaching younger colleagues; the tool might facilitate 


\section{Niraula et al}

a more rapid acquisition of higher surgical knowledge. ${ }^{12}$ Although there is no conclusive evidence that minimally invasive microdiscectomy is superior to open discectomy, the perception of superiority may be so powerful that it motivates the patient to request only minimally invasive microdiscectomy. ${ }^{20}$

This newer minimal invasive technique have mixed and inconsistentresults. Somestudies showed microdiscectomy is superior to open discectomy ${ }^{1,5,6,8,13}$ whereas some studies showed the results are similar to open discectomy. ${ }^{6,12,14,19}$ Overall the comparison of the procedures were done on the basis of neurological outcomes, pain relief, hospital stay, operative time, hospital costs, and post-operative complications.

\section{Rational}

No study has been done to see the pattern of improvement in Neurological improvement in different post-operative days as compared to pre-operative status with respect to muscle power, sensory status and SLR. The pattern of improvement is not keenly observed although same data set and finding is seen differently would yield these facts. This information is beneficial in management part to surgeons, relatives and the patients.

\section{Objective}

To assess pattern of neurological outcomes in patients with lumbar disc herniation after microdiscectomy interms of muscle power, sensory status and SLR.

\section{Materials and Methods}

A Quasi experimental study was conducted among patients admitted in Neurosurgery department of Mayo Hospital/King Edward Medical University, Lahore from September 2014 to December 2015 with diagnosis of Lumbar disc herniation suggested by clinical findings and confirmed by plain MRI. King Edward Medical University founded in 1860 is located in Lahore, Pakistan. ${ }^{20}$ Until 2006 it was a medical college and was elevated to degree awarding institution then. The university is named after the Edward VII and its attached hospital Mayo Hospital was erected in 1870. The department of Neurosurgery where this study was conducted was $1^{\text {st }}$ Neurosurgical center to open in Punjab Province of Pakistan, the most populated and developed province of Pakistan which harbors the cultural city, Lahore. King Edward Medical College was established in 1860 as the Lahore Medical College. It is the fourth oldest medical school in South Asia, after Medical College Kolkatta (January 28, 1835), Madras Medical College, Chennai (February 2, 1835) and Grant Medical College, Bombay (1845). ${ }^{20}$
Patients ranged from 14-70 year with sample size of 70 of both genders as calculated by taking prevalence (percentage) of neurological improvement in patient with lumbar disc herniation as $76 \%{ }^{16}$, confidence level of $95 \%$ and permissible error of $10 \%$. Patient with previous disc surgeries, other spinal pathologies and with systemic illness were excluded from the study. In study duration of a year, samples were selected by non-probability sampling technique as it was a hospital based study with no sampling framework is available so all consecutive patients with lumbar disc herniation meeting inclusion criteria were studied until sample size was achieved.

At first data collection permission was taken from the University and Neurosurgery department. The detailed history was taken and relevant neurological examination was performed in patients attending Neurosurgery out-patient department of Mayo hospital, Lahore with complains of symptoms associated to lumbar disc herniation. After history taking, examination done and confirming the disc pathology lied at lumbar region, MRI was ordered (plain). All preoperative investigation and anesthetic fitness for general anesthesia was from either outdoor or indoor basis. With patient ready for surgery with all investigations done, getting anesthesia fitness and arranged 1 pint of blood they were put on elective operation list. Data was only collected if patient met inclusion criteria. Informed consent was taken from patient if they were capable of doing so if not was taken from their nearest relatives available. The patient not under the study was dealt as per ward rule but they were not included in the study. The candidates, who gave consent, fit for general anesthesia, met inclusion criteria were then asked for detail history, and neurological examination was performed before the surgery. Pre-tested, interviewer administered questionnaire was used to collect data socio-demographic variables, disease profile whereas MRI findings were noted in checklist. For standardized and unbiased results the surgery was performed only by the consultants and residents assisted them. Post-surgical neurological examination was conducted on $1^{\text {st }}, 7^{\text {th }}, 21^{\text {st }}$ and $42^{\text {nd }}$ post-operative day. The patient $1^{\text {st }}$ post-operative day's neurological examination was performed in the ward, whereas on $7^{\text {th }}, 21^{\text {st }}$ and $42^{\text {nd }}$ day the assessment was done in the neurosurgery ward or out-patient department depending on their day of discharge. The validation of the Performa was done with the help of a Neurosurgeon and a Statistician.

After data collection was completed, they were carefully checked for possible mistakes. Then they were exported and analyzed in SPSS version 15. Continuous variables either background, neurological status were expressed in the form of Mean \pm SD. Categorical variables 


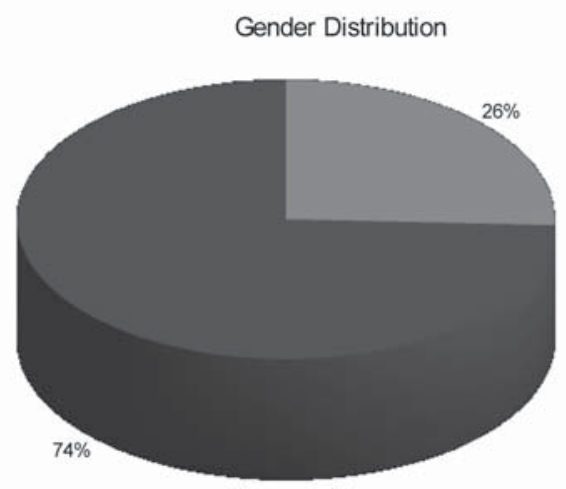

Figure 1: Gender distribution

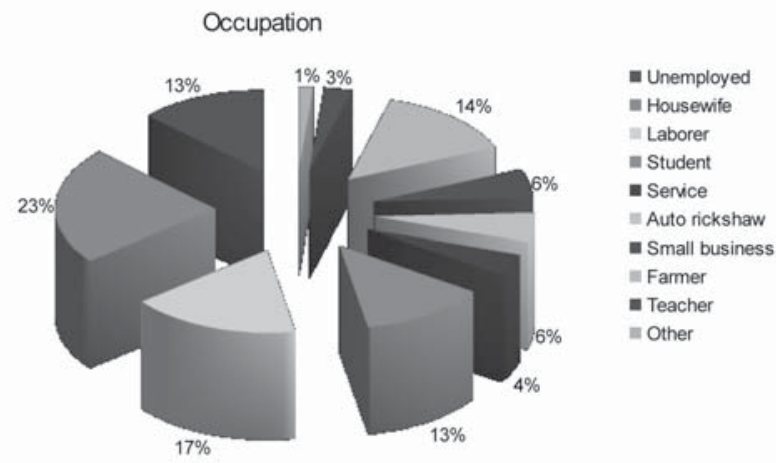

Figure 2: Occupation

were expressed in the form of frequency and percentage. Mc Neumer's chi square test and paired t test were used to see association between pre-operative and post-operative Neurological status depending on their nature viz: qualitative or quantitative respectively. P value of $<0.05$ was regarded as level of significance and all tests were 2 tailed.

\section{Results}

Mean age of the patients was 37.6 years and the standard deviation was 13.0 years. Patients' age ranged from 14 to 70 making median age as 35.0 years (Table 1). Sex distribution of the patients was fairly male dominate $(\mathrm{n}=52, \%=74.3)$ (Figure 1). Majority of the patients were housewives $(n=16, \%=22.9)$ and in terms of occupation where both males and females may actively get involved, Laborer category had maximum number of patients $(\mathrm{n}=12, \%=17.2)$. Only few had white collar jobs (Figure 2). Major portion of the samples were illiterate $(n=51$, $\mathrm{n}=72.9$ ), about $15 \%$ held bachelor's degree and above (Figure 3).

More than quarter $(27.1 \%)$ of the patients had no motor deficits and the most affected myotome was right L5 $(\mathrm{n}=16, \%=22.6)$. The overall range of pre-operative muscle power was $0-5$ (Table 2). Nearly half (44.3\%)

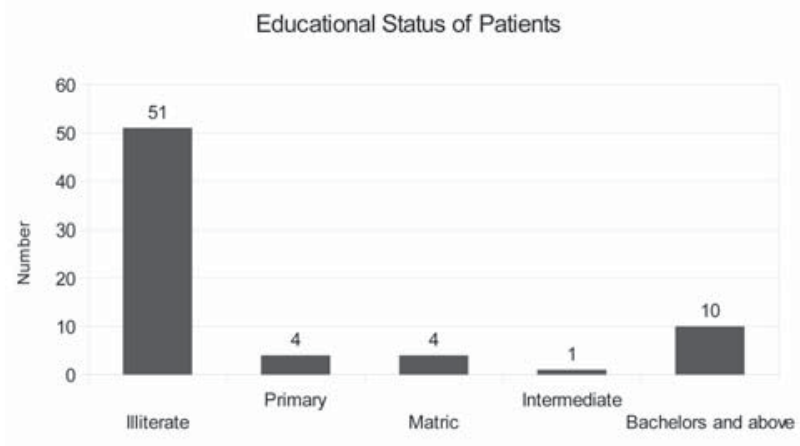

Figure 3: Education

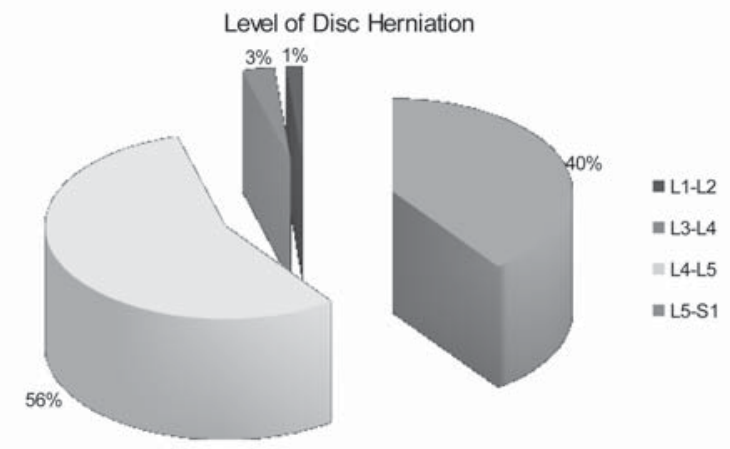

Figure 4: Level of Disc herniation

had no sensory deficit in preoperative period. The most commonly affected dermatome before surgery was Left S1 $(\mathrm{n}=11, \%=15.7)$, where 8 had complete losses of sensation and 3 had diminished sensation. In total 23 (32.9\%) had lost sensation and $15(21.4 \%)$ had diminished sensation in their respective affected dermatomes because of nerve compression by herniated disc (Table 3). Fairly right and left side equally had SLR distribution with minimum SLR as 20 and maximum as 80 degrees. Mean SLR value was 52.9 and 50 degrees was the cut off to divide the samples into equal numbers (Table 4). Figure 2.2 shows level of disc herniation as reveled from MRI lumbosacral spine. The most common level of disc herniation was L4-L5 $(\mathrm{n}=39, \%=55.7)$. Level L4-L5 and L5-S1 contributed to $95.7 \%(n=67)$ of total disc herniation (Figure 4). Referring to the sagittal and axial slices of MRIs most common presentation of the herniated disc were prolapse $(n=30)$ and extrusion $(n=30)$, both contributing to more than $85 \%$ of the presentation (Figure 5).

\section{MRC grade}

Pre-operative mean MRC grade was 3.4, which improved to 4.0 on $1^{\text {st }}$ post-operative day. It is $15 \%$ improvement from the baseline status. The improvement was steady on $7^{\text {th }}$ postoperative day with mean MRC score 4.4 i.e. $22.7 \%$ improvement from the baseline. 
Niraula et al

\begin{tabular}{|l|l|l|l|}
\hline Mean (years) & Median (years) & Standard Deviation (years) & Range (years) \\
\hline 37.6 & 35.0 & 13.0 & $14-70$ \\
\hline
\end{tabular}

Table 1: Age distribution

\begin{tabular}{|c|c|c|c|c|c|c|c|}
\hline \multirow[t]{2}{*}{ S.no. } & \multirow[t]{2}{*}{ Myotome } & \multirow[t]{2}{*}{ Number } & \multirow[t]{2}{*}{ Percentage } & \multicolumn{4}{|c|}{ Muscle Power by MRC grade } \\
\hline & & & & Mean & Median & SD & Range \\
\hline 1. & None & 19 & 27.1 & 5.0 & 5.0 & 0.0 & $5-5$ \\
\hline 2. & Right L2 & 1 & 1.4 & 3.0 & 3.0 & 3.0 & $3-3$ \\
\hline 3. & Right L5 & 16 & 22.9 & 2.9 & 3.0 & 0.9 & $2-4$ \\
\hline 4. & Right S1 & 10 & 14.3 & 3.0 & 3.0 & 0.8 & $2-4$ \\
\hline 5. & Left L5 & 9 & 12.9 & 2.4 & 2.0 & 1.2 & $0-4$ \\
\hline 6. & Left S1 & 13 & 18.6 & 2.4 & 3.0 & 1.1 & $0-4$ \\
\hline 7. & Total & 70 & 100 & 3.4 & 3.0 & 1.3 & $0-5$ \\
\hline
\end{tabular}

Table 2: Pre-operative Affected Myotome and pre-operative power

\begin{tabular}{|l|l|l|l|l|l|l|}
\hline S.no. & Dermatome & Number & Percentage & Lost & Dimished & Normal \\
\cline { 5 - 7 } & & & & n (\%) & n (\%) & n (\%) \\
\hline 1. & None & 31 & 44.3 & $0(0)$ & $0(0)$ & $31(100)$ \\
\hline 1. & Right L2 & 1 & 1.4 & $0(0)$ & $1(100)$ & $0(0)$ \\
\hline 2. & Right L4 & 2 & 2.9 & $1(50)$ & $1(50)$ & $0(0)$ \\
\hline 3. & Right L5 & 11 & 15.7 & $5(45.5)$ & $5(45.5)$ & $1(9.0)$ \\
\hline 4. & Right S1 & 8 & 11.4 & $4(50)$ & $4(50)$ & $0(0)$ \\
\hline 5. & Left L5 & 6 & 8.6 & $5(83.3)$ & $1(16.7)$ & $0(0)$ \\
\hline 6. & Left S1 & 11 & 15.7 & $8(72.7)$ & $3(27.3)$ & $0(0)$ \\
\hline 7. & Total & 70 & 100 & $23(32.9)$ & $15(21.4)$ & $32(45.7)$ \\
\hline
\end{tabular}

Table 3: Pre-operative Affected Dermatomes and pre-operative level of sensation

\begin{tabular}{|c|c|c|c|c|c|c|c|}
\hline \multirow[t]{2}{*}{ S.no. } & \multirow[t]{2}{*}{ SLR side } & \multirow[t]{2}{*}{ Number } & \multirow[t]{2}{*}{ Percentage } & \multicolumn{4}{|c|}{ SLR value } \\
\hline & & & & Mean & Median & SD & Range \\
\hline 1. & Right & 34 & 48.6 & 52.8 & 50.0 & 15.0 & $20-80$ \\
\hline 2. & Left & 36 & 51.4 & 52.9 & 55.0 & 15.7 & $25-75$ \\
\hline 3. & Total & 70 & 100 & 52.9 & 50.0 & 15.3 & $20-80$ \\
\hline
\end{tabular}

Table 4: Pre-operative SLR and pre-operative SLR value

\begin{tabular}{|l|l|l|l|l|l|}
\hline Variables & Pre op & $\mathbf{1}$ st Post op & 7 Post op & 21 Post op & 42 Post op \\
\hline \multirow{2}{*}{$\begin{array}{l}\text { Musclepower(MRC } \\
\text { grade) }\end{array}$} & 3.4 & 4.0 & 4.4 & 4.7 & 4.7 \\
\cline { 2 - 6 } & Improvement \% & $15 \%$ & $22.7 \%$ & $27.7 \%$ & $27.7 \%$ \\
\cline { 2 - 6 } & P value & $\mathbf{0 . 0 0 1}$ & $\mathbf{0 . 0 0 1}$ & $\mathbf{0 . 0 0 1}$ & $\mathbf{0 . 0 0 1}$ \\
\hline \multirow{3}{*}{$\begin{array}{l}\text { Sensation } \\
\text { matomes) }\end{array}$} & 32 & 35 & 38 & 43 & 51 \\
\cline { 2 - 6 } & Improvement \% & $8.6 \%$ & 15.8 & 25.6 & 37.6 \\
\cline { 2 - 6 } & P value & $\mathbf{0 . 0 0 1}$ & $\mathbf{0 . 0 0 1}$ & $\mathbf{0 . 0 0 1}$ & $\mathbf{0 . 0 0 1}$ \\
\hline \multirow{3}{*}{ SLR } & 52.9 & 98.6 & 98.6 & 98.6 & 98.6 \\
\cline { 2 - 6 } & Improvement \% & 46.3 & 46.3 & 46.3 & 46.3 \\
\cline { 2 - 6 } & P value & $\mathbf{0 . 0 0 1}$ & $\mathbf{0 . 0 0 1}$ & $\mathbf{0 . 0 0 1}$ & $\mathbf{0 . 0 0 1}$ \\
\hline
\end{tabular}

Table 5: Pattern of improvement 


\begin{tabular}{|c|c|c|c|c|}
\hline \multicolumn{2}{|c|}{ Variables } & Sensory & MRC & SLR \\
\hline \multirow[t]{2}{*}{ Sensory } & Correlation coefficient & \multirow[b]{2}{*}{ N/A } & 0.9 & 0.7 \\
\hline & P Value & & 0.04 & 0.2 \\
\hline \multirow[t]{2}{*}{ MRC } & Correlation coefficient & 0.9 & \multirow[b]{2}{*}{ N/A } & 0.9 \\
\hline & P Value & 0.04 & & 0.04 \\
\hline \multirow[t]{2}{*}{ SLR } & Correlation coefficient & 0.7 & 0.9 & \multirow[b]{2}{*}{ N/A } \\
\hline & P Value & 0.2 & 0.04 & \\
\hline
\end{tabular}

Table 6: Correlation among MRC, sensation and SLR

Improvement was also seen on $21^{\text {st }}$ post-operative day to $27.7 \%$ from baseline and $5 \%$ from $7^{\text {th }}$ post-operative day. There was no improvement or deterioration in muscle power from $21^{\text {st }}$ to $42^{\text {nd }}$ post-operative day. All the MRC finding in each post-operative days were statistically significant with the baseline by paired test $(p=0.001)$ (Table 5).

\section{Sensory status}

Pre-operatively only $32(45.7 \%)$ patients has normal sensation over affected dermatomes. On $1^{\text {st }}$ postoperative day 35 patients has normal sensation with $8.6 \%$ improvement. On $7^{\text {th }}$ post-operative day 38 had normal sensations with $15.8 \%$ improvement from baseline and $7.2 \%$ from $1^{\text {st }}$ post-operative day. Improvement was marked in $21^{\text {st }}$ and $42^{\text {nd }}$ post-operative day with $25.6 \%$ and $37.4 \%$ improvement respectively. Sensory function although started with slight improvement but at the end of $42^{\text {nd }}$ post-operative day improved was significantly higher that than of muscle power (37.6\%vs $27.7 \%)$. All the sensory finding in each post-operative days were statistically significant with the baseline by paired t test $(\mathrm{p}=0.001)$ (Table 5).

\section{SLR}

Baseline SLR in affected limbs was 52.9 degrees in average pre-operatively. Total improvement in SLR was seen in $1^{\text {st }}$ post-operative day itself. After $1^{\text {st }}$ postoperative day till $42^{\text {nd }}$ post-operative day there was no

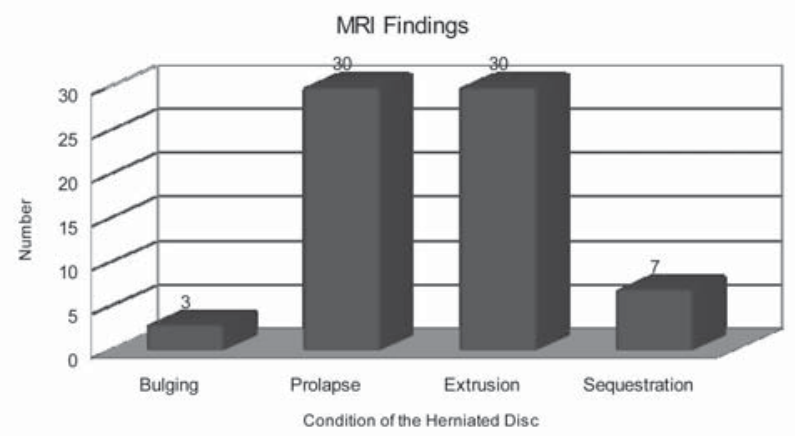

Figure 5: MRI findings change in SLR values. So, SLR was the best measure that got improved immediately and to the maximum extends in $1^{\text {st }}$ post-operative day.

\section{Overall improvement}

Figure 6 shows improvement of MRC, sensory status and SLR values from pre-operative status till $42^{\text {nd }}$ postoperative day. Since all 3 have different units, to make uniform representation improvement of all 3 variables is expressed in the form of improved percentage. Irrespective of any value baselines for all 3 variables are made zero. SLR improved on $1^{\text {st }}$ post-operative day and the improvement was $46.3 \%$ which was steadily thought remaining follow up periods. Secondly, Sensory status nearly followed a pattern of a straight line, which kept on improvement in successive post-operative days. Muscle power also improved from the baseline by $15 \%$ on $1^{\text {st }}$ post-operative day with maximum improvement on $21^{\text {st }}$ post-operative day and remained static till $42^{\text {nd }}$ postoperative day. Correlation among MRC, sensation and SLR is shown in the Table 6.

\section{Discussion}

Mostly SLR improvement was seen $1^{\text {st }}$ in all the past studies ${ }^{6,12,17}$, except few ${ }^{5,8}$. Muscle power was seen to improve only after $\operatorname{SLR}^{4,15,17}$, whereas sensory improvement was least and seen at the last ${ }^{5}$. In our study

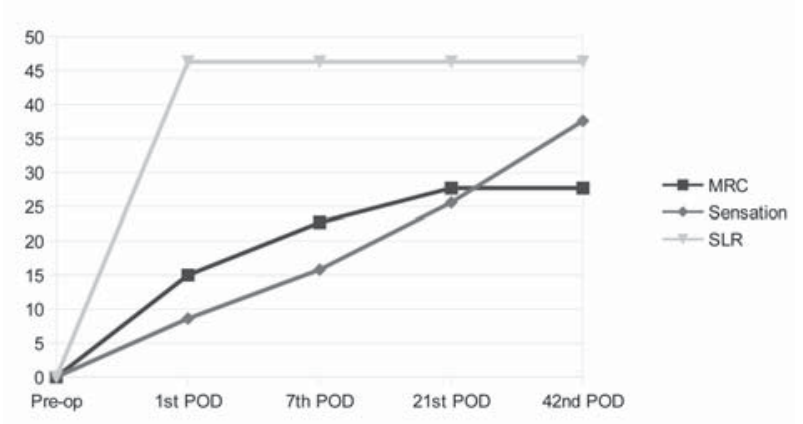

Figure 6: Improvement curve 


\section{Niraula et al}

the total SLR improvement was seen all in $1^{\text {st }}$ POD. In rest of the follow up periods it was static, neither had it improved nor did it deteriorate.

The diagnostic and therapeutic management of patients with sciatica is characterized by a considerable variation within and between countries. There is, for example, a striking variation in the surgery rates for lumbar discectomy between countries ${ }^{3}$. A more recent publication confirms the still large variation of disk surgery, even within one country ${ }^{23}$. The natural history of LSRS is in general favourable. In 60-80 percent of patients, the leg pain decreased or disappeared within 6-12 weeks after onset $^{21,22}$. The minority with lasting complaints beyond three months further decreases with time. At one year only a small proportion of herniated disks continue to produce discomfort and disability. At present it is not possible to identify these latter groups of patients in an early stage of their disease by means of intensity of pain, neurological deficit, root irritation signs, or diagnostic imaging. For this reason it is not helpful to perform early diagnostic imaging (CT or MRI), unless a disease entity different from disk herniation is considered. After the indication for surgery has been set diagnostic imaging is helpful in defining the exact site of disk herniation and its anatomical relationship with the nerve root involved. Since the first publication on lumbar disk surgery by Mixter and Barr many studies have demonstrated the success of surgery for the treatment of LSRS. Unfortunately only a few prospective studies investigated the difference in outcome between surgical and conservative care. $2,7,8,12,21,22$

In spite of the known favorable natural course the surgical rate in the Netherlands is quite high ${ }^{24}$. Although relief of complaints was twice as fast for sciatica patients treated with early surgery, this multicenter randomized trial demonstrated that this strategy did not result in a better overall 1-year functional recovery rate when compared with a policy of prolonged conservative treatment with eventually offering delayed surgery. During one year 89 percent of patients in the early surgery group and 39 percent of the conservative treatment group were treated by microdiscectomy.

Majority of patient had pre-operative SLR in between 30-60 degree, $77.3 \%$ in Khan $Z^{9}, 64.3 \%$ in current study and there is no mention about it in Raja RA ${ }^{17}$ study. After the surgery in $1^{\text {st }}$ postoperative day SLR improvement was seen in $88.4 \%$ cases in Khan $Z$ and $94.3 \%$ in the current study. In all 3 cases most common level of disc herniation was L4-L5 and L5-S1. These 2 levels contributed to $85.8 \%$ in Khan Z study, $100 \%$ in Raja RA and $95.7 \%$ in the current study. Preoperative leg pain was most common in the current study (98.6\%) whereas Khan Z had $42 \%$ and Raja RA had $69 \%$ cases with leg pain. In case of back pain too the current study had the majority of samples (78.6\%); Khan Z had 38\% patient and Raja RA had $84.4 \%$ cases with back pain preoperatively. As we compare $1^{\text {st }}$ postoperative day improvement in the leg pains; $77.1 \%$ were improved in the current study whereas $91.5 \%$ and $82.2 \%$ respectively improved in Khan Z and Raja RA studies.

\section{Conclusion}

Muscle power and sensory improvement follows same improvement pattern in patient in LDH after microdiscectomy whereas maximum SLR improves in the $1^{\text {st }}$ POD itself.

\section{Conflict of Interest}

Authors declare no competing financial or nonfinancial conflict of interest.

The study is not funded by any pharmaceutical company directly or indirectly involved in production of medication, instruments used for the management of this condition.

\section{References}

1. Arts MP, Peul WC, Brand R et al. Cost-effectiveness of microendoscopic discectomy versus conventional open discectomy in the treatment of lumbar disc herniation: a prospective randomized controlled trial. BMC Musculoskelet Disord 7: 42, 2006

2. Atlas SJ, Deyo RA, Keller RB et al. The Maine Lumbar Spine Study, Part II. 1-year outcomes of surgical and nonsurgical management of sciatica. Spine 21:1777-1786, 1996

3. Cherkin DC, Deyo RA, Loeser JD, Bush T, Waddell G. An international comparison of back surgery rates. Spine 19:1201-1206, 1994

4. Chi JH, Dhall SS, Kanter AS, et al. The miniopen transpedicular thoracic discectomy: surgical technique and assessment. Neurosurg Focus 25: E5 2008

5. Cole JS, Jackson TR. Minimally invasive lumbar discectomy in obese patients. Neurosurg 61: 539544, 2007

6. German JW, Adamo MA, Hoppenot RG, Blossom JH, Nagle HA. Perioperative results following lumbar discectomy: comparision of minimal invasive discectomy and standard microdiscectomy. Neurosurg Focus 25: E20, 2008

7. Hakelius A. Prognosis in sciatica. A clinical followup of surgical and non-surgical treatment. Acta Orthop Scand Suppl 129:1-76, 1970 


\section{Lumbar Disc Herniation}

8. Harrington JF, French P. Open versus minimally invasive lumbar microdiscectomy: comparison of operative times, length of hospital stay, narcotic use and complications. Minim Invasive Neurosurg 51:30-35, 2008

9. Khan Z, Sharafat S, Ali M. Surgical outcome after microdiscectomy for lumber disc herniation. J Med Sci 21:74-76, 2013

10. Lau D, Han SJ, Lee JG, Lu DC, Chou D. Minimally invasive compared to open microdiscectomy for lumbar disc herniation. J Clin Neurosci 18:81-84, 2011

11. Malter AD, McNeney B, Loeser JD, Deyo RA. 5-year reoperation rates after different types of lumbar spine surgery. Spine 23:814-820, 1998

12. Mannion AF, Porchet F, Kleinstiick FS et al. The quality of spine surgery from the patient's perspective. Part 1: The Core Outcome Measures Index in clinical practice. Eup Spine Journal 18 : 367-373, 2009

13. McLoughlin GS, Fourney DR. The learning curve of minimally-invasive lumbar microdiscectomy. Can J Neurol Sci 35:75-78, 2008

14. Nowitzke AM. Assessment of the learning curve for lumbar microendoscopic discectomy. Neurosurg 56:755-762, 2005

15. Osterman H, Seitsalo S, Karppinen J, et al. Effectiveness of microdiscectomy for lumbar disc herniation: a randomized controlled trial with 2 years of follow-up. Spine 31:2409-2414, 2006

16. Postacchini F, Giannicola G, Cinott Gi. Recovery of motor deficits after microdiscectomy for lumbar disc herniation. J Bone Joint Surg [Br] 84:1040-1045, 2002

17. Raja RA, Khemani VD, Lakhair MA, Khan SA. Discectomy in single level lumbar disease. J Ayub Med Coll Abbottabad 24: 81-83, 2012

18. Righesso O, Falavigna A, Avanzi O. Comparison of open discectomy with microendoscopic discectomy in lumbar disc herniations: results of a randomized controlled trial. Neurosurg 61:545-549, 2007

19. Ryang YM, Oertel MF, Mayfrank L et al. Standard open microdiscectomy versus minimal access trocar microdiscectomy: results of a prospective randomized study. Neurosurg 61:174-182, 2008

20. The King Edward Medical University, Lahore Act 2005. Punjab Gazette (Extraordinary): pp 53935410. 12 May 2005

21. Weber H. Lumbar disc herniation. A controlled, prospective study with ten years of observation. Spine 8:131-140, 1983

22. Weber H. Lumbar disc herniation. A prospective study of prognostic factors including a controlled trial. Part II. J Oslo City Hosp 28:89-113, 1978

23. Weinstein JN, Lurie JD, Olson PR, Bronner KK, Fisher ES. United States' trends and regional variations in lumbar spine surgery: 1992-2003. Spine 31:2707-2714, 2006

24. Wu X, Zhuang S, Mao Z, et al. Microendoscopic discectomy for lumbar disc herniation: surgical technique and outcome in 873 consecutive cases. Spine 31:2689-2694, 2006 